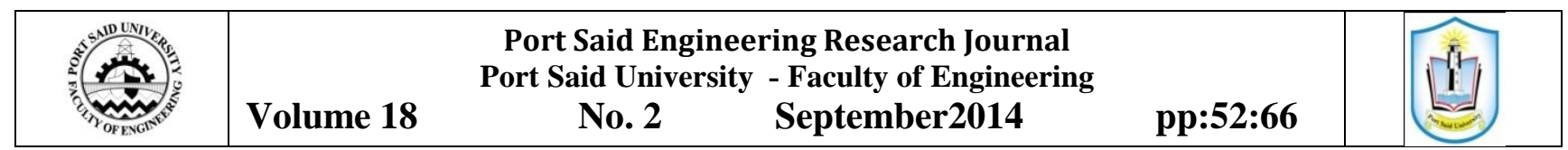

\title{
Transport Accessibility: A Tool for Identification of Activity- Based Destination Choice Model for Port-Said City, Egypt
}

\author{
Marwa E. El-Bany ${ }^{1} /$ Mohamed M. Shahin ${ }^{2} /$ Ibrahim H. Hashim ${ }^{3} /$ Mohamed S. Serag ${ }^{4}$
}

\begin{abstract}
The destination choice is an essential step of the travel demand modeling. Many previous studies were concentrated on land use which means that the utilization of land for different activities such as residential, commercial, industrial, educational, etc. is linked with travel demand. Accessibility is often seen to be an important determinant of the activities destination choice. This study is concerned with using the accessibility concept to investigate the utility function of the activity destination choice. A case study is Port Said (PS) City in Egypt. The characteristics of time, cost, and income level are obtained from activity based comprehensive transportation surveys. The benefit or utility of choosing a specific activity (BM values) are estimated based on the calculation of accessibility benefit from time-space geography measures for different zones in PS. Binary and Multinomial logit models were used for daily activities performed by individuals. During different time segment, the model predicts individual probability of choosing one of the following five activities: work, shopping, school, university, and Leisure. The accessibility benefits are examined associating with decreasing travel time (public transport-oriented development), improving income level for poor, and restricting car use. Finally, the model approved to be sensitive to different measures and hence it can be used as an effective informative tool to the decision makers.
\end{abstract}

Key words: Accessibility-Benefit, Destination Choice, Activity-Based (AB) model, Utility Function

\section{INTRODUCTION}

The activity destination choice modeling is the second module of Activity-Based travel demand estimation. The traditional destination choice models depend on the policy recommendations from urban land use where they neglect the temporal and transportation effects [1]. The probability of choosing the location depends on the spatial and temporal attributes [2]. The trip generation and distribution are processes affected by activity destination choice that needs utility function to perform it during different segments of the day.

Accessibility is often seen to be an important determinant of the activities location [3]. There is a fact based on the premise that "the choice of an activity increases as the accessibility benefit of the activity increases" as shown in the trend in Figure $\mathbf{1}$ Accessibility Benefit (BM) is an accessibility index measure of activity location opportunity like $A i$ [4]. Thus, $\mathrm{BM}$ values may be indicators of destination choice behavior instead of the activity utility of the derived Activity-Based (AB) model.

${ }^{I}$ Assistant lecturer of Transportation and Traffic Eng., Faculty of Engineering, Port-Said University, Egypt.

${ }^{2}$ Professor of Transportation and Traffic Eng., Faculty of Engineering, Alexandria University, Egypt.

${ }^{3}$ Associate professor of Transportation and Traffic Eng., Faculty of Engineering, Menoufia University, Egypt.

${ }^{4}$ Associate professor of Transportation and Traffic Eng., Faculty of Engineering, Port-Said University, Egypt.
Activity-Based (AB) model deals with a travel as a derived demand from the need to pursue activities distributed over space and time. In AB models, travel is derived from activities participation and depends on the organization of those activities. These models describe which activities people pursue, where, when, for how long, and with whom transport modes are involved. Also, it gives the ability to know how these activities are scheduled, given the locations and attributes of potential destinations, the state of the transportation network, the aspects of the institutional context, and the personal and household characteristics. Daily activity patterns, rather than single trips, became the basic behavioral unit [5]. Figure 2 illustrates an example of the Activity Based modeling framework.

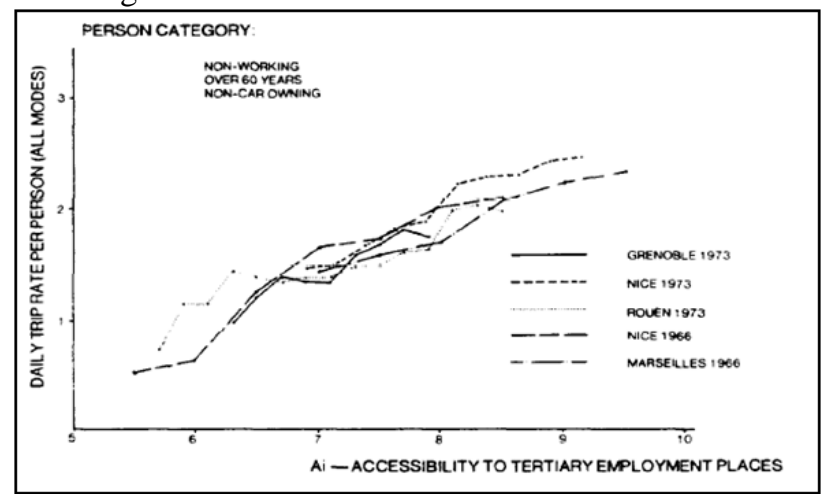

Figure 1: The Effect of Accessibility on Trip Rates [6] 


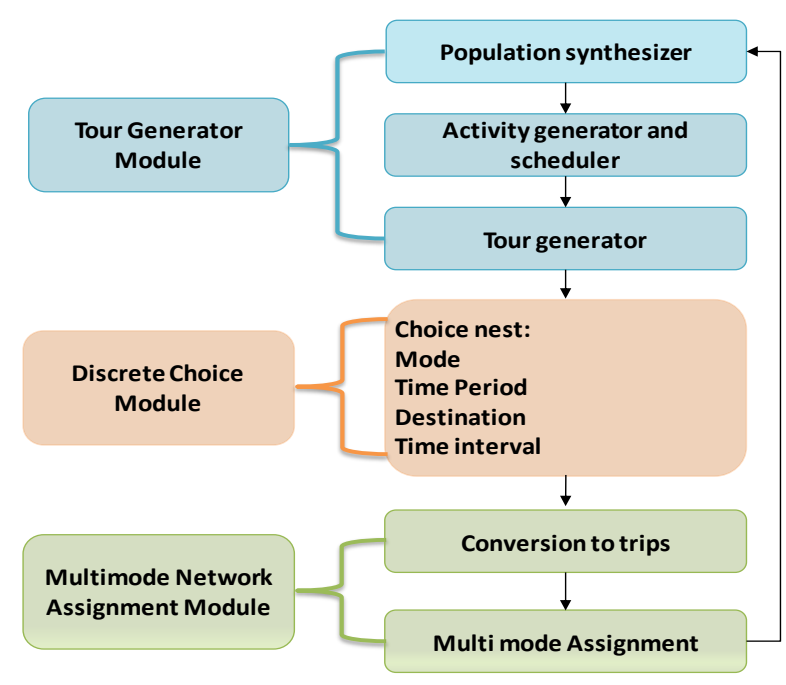

Figure 2: Activity Based Modeling Framework [7]

The advantages of the activity-based approach are summarized in Kitamura (1996)[8] as follows:

$>$ Daily behavior that treats a daily activity-travel pattern as a whole, thus avoids the shortcomings of the conventional trip-based methods;

$>$ Realism that incorporates various constraints governing trip making, facilitating realistic prediction and scenario analyses;

$>$ Induced demand that represents activity engagement behavior, the activity-based approach can rigorously address the issue of induced or suppressed demand.

$>$ Time of day that predicts travel behavior along a continuous time axis;

> Travel demand Management (TDM) evaluation that is capable of realistically assessing the impact of TDM measures on the entire daily travel demand; and

$>$ Flexible and versatile that can be modified for specific study objectives or to address various policy scenarios to evaluate effects of day-care facilities at work, extended transit service hours, or new transit service.

The activity-based approach implies an expansion of the analytical scope because its subject is not limited to the trip. This naturally leads to increased levels of data requirements and analytical complexities. The advantages offered by this approach are in particular the ability to overcome the limitations of the conventional trip-based methods and to address policy options.

\section{Accessibility Concepts}

The accessibility indicates the collective performance of land use and transportation systems and determines how well that complex system serves its residents. It plays an important role in policy making. For example, when measuring accessibility to jobs, the attraction value can be the number of jobs at the various potential destinations, while for shopping centers this can be the number of shops in the center. The impedance function decreases the probability of being attracted to such destinations based on distance or travel time. The measures of accessibility seek to give an operational form to the concept of ease or difficulty of reaching activities.

\subsection{Accessibility Measures Based on Time-Space Geography}

One of renowned attitudes of accessibility measures is Hagerstrand's time-space geography measures [9]. It illustrates the activity choice of an individual in terms of taking part in activities. Burns (1979) [10] developed an analytical formulation to incorporate all the components of accessibility, i.e. transportation, temporal, and spatial components. The accessibility benefit measure proposed by Burns was improved and adapted for application to rural accessibility planning in developing countries by Odoki (1992, 1998, 1998a)[11,12,13]. This study presumes accessibility to initiate and promotes urban areas development. To illustrate Time-Space model, consider the simple case of an individual constrained to be at home between time $t 2$ and $t 1$ as shown in Figure3. This may be due to the individual's own physiological needs. Assuming that he/she travels at a maximum speed, these delineate behavioral time-space autonomy $[4,14,15]$. For example, if the individual chooses to work at location $k$ from time $t 3$ to $t 4$ the time-space is described by the thick line.

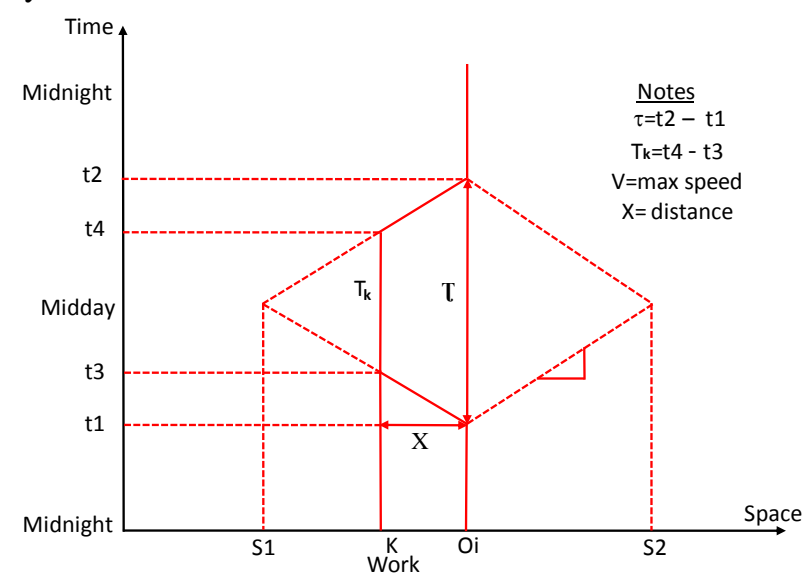

Figure 3: Time-Space Diagram of an Individual who Works at Location $k[4,14,15]$

The major objective of the Activity-Based Choice approaches is to replicate activity travel processes of individuals. These choice processes include such dimensions as activity type choice, time of day choice, trip chaining or linking choice, joint versus solo activity engagement choice, destination choice, mode choice, activity sequencing decisions, and activity time allocation (duration) decisions. Many of these choice processes are discrete in nature (e.g., activity type choice, time of day 
period choice, mode and destination choices), while others are continuous (e.g., activity duration).

Individual and activity place attributes are vital items of urban travel behavior choice model. Individual attributes such as income, gender, car ownership and activity place attributes such as time and space to reach the activity place are important components of ability to reach the chosen place which can be summarized as accessibility that is equally useful in considering the best use of existing resources. Also, it enables transport planners to consider non-transport (such as land-use) solutions to their problems.

\subsection{Components of Accessibility-Benefit based on Time-Space Geography}

The Accessibility-Benefit (utility function) combines the following three components of accessibility, namely:

- The disutility of travel, i.e. the transportation component;

- The benefit of location-activity, i.e. the spatial component; and

- The benefit of time, i.e. the temporal component.

These components of accessibility are collected into a single framework by defining location opportunity approach as:

$B M=q(x) . a_{k}, u\left(T_{k}\right)$

where:

$B M$ : an accessibility index measure of activity destination opportunity (Benefit Measure)

$q(x) \quad$ : transportation component

$a_{k} \quad:$ spatial component or attractiveness measure or location opportunity measure

$u\left(T_{k}\right) \quad$ : temporal component

The key improvement includes the enhancement of utility functions in developing countries that introduce income constraint into the accessibility measure. Each of these components will be illustrated in the following paragraphs.

\subsubsection{Transportation Component $q(x)$}

The value of an individual transportation opportunity decreases with distance because the amount of time that can be spent at location $\left(t_{2}-t_{1}\right)$ decreases and then the monetary travel cost increases. This effect is incorporated by deterrence function $q(x)$ that decreases with distance. This function should have a maximum for an activity that doesn't require travel $(x=0)$. A simpler form of $q(x)$ is given as follows[15]:

$q(x)=\exp \left[-g_{t} x\right]$ where:

$q(x)$ : is the utility index to an individual for travelling a distance $\mathrm{x}$

$g_{\mathrm{t}} \quad$ : is the generalized travel time cost per $\mathrm{km}$ function

The generalized travel time is a crucial one of inserting the income effect into the function to produce better deterrence function for transportation component in developing countries. Ali (2009)[15] argued that the generalized travel time for developing countries can be presented as follows:

$g_{t}=\frac{m}{\alpha I}+t$

where:

$m \quad:$ the monetary travel cost

$t \quad:$ the travel time

$\alpha I \quad$ : value of travel time

The above model has been made for developing countries whose people, having income $I$, value their travel time at a rate of $\alpha I$ per hour. Therefore the transportation component can be written as:

$q(x)=\exp \left[-\left(\frac{m}{\alpha I}+\frac{1}{v}\right) 2 x\right]$

where:

$v$ : average speed of travel per km per hour; note that $v=$ $1 / t$

\subsubsection{Temporal Component $u\left(T_{k}\right)$}

Temporal Component reflects the temporal constraints such as the time available for individuals to participate in certain activities (e.g. work, recreation). In defining the time utility function, the attention has been given to the amount of time available at activity locations. The marginal utility of the time individuals can spend at a location is constant for mandatory activities and not constant for non-mandatory activities. The effect of an individual's income has been considered indirectly within the temporal component through the model parameter $(\gamma)$ which depends on the characteristics of individual and the type of activity. For individuals with low-income, they will have high values of $\gamma$ with work activities that they need to earn money but low values for activities that require spending of income such as shopping. It is important to take the time utility function when evaluating strategies and policies that can be determined from [12]:

$\boldsymbol{u}\left(\boldsymbol{T}_{\boldsymbol{k}}\right)=\boldsymbol{h}^{\gamma}\left(\tau-\frac{2 x}{v}\right)^{\gamma}$

where:

$T_{k}$ :the time available for participating in an activity location $\mathrm{k}$ 
$\gamma$ :the marginal utility of time parameter ; $\gamma>1$ depends on individual characteristics and

the

type of activity

$h$ :the scale parameter and a function of wage received in welfare arising from the activity

$\tau$ :the time budget available between coupling constraints. It is equal to total daily time budget; from urban household survey this value is set to be equal to 16 hours.

The parameter $h$ is a scale parameter used as a measure of utility (per unit of time) that the person is engaged in the activity. The value of $h$ for the activities Work, School and University may be taken as unity. This notion is incorporated in the development of the mathematical form for the value of the parameter $h$. The expression used for the parameter $h$ for each activity $i$ is:

$h_{j}=\left\{\begin{array}{l}1 ; \text { if } j=\text { work, school } \\ \frac{T_{j}}{T_{w}} ; \text { if } j=\text { shopping }\end{array}\right.$

where:

$h \quad$ : measure of utility parameter for activity $j$

Tj : actual duration for non- mandatory activity $\mathrm{j}$

Tw : actual duration for mandatory activity $\mathrm{w}$

The marginal utility of time parameter $\gamma$ is related to the activity type and individual type [4]. With the help of case studies, Odoki (1998a)[13] argued that participation in earning activities gives the relative weighting of the value of $\gamma$ for work as well as other activities. The functional form developed by (Ali, 2009)[15] for the marginal utility of time parameter $\gamma$ incorporates these notions, i.e.:

$\gamma_{j}^{i}=\left[1.5-\frac{1}{\exp \left(a_{j}^{i}\right)^{0.15}}\right]$

where:

$\gamma_{j}^{i}$ : value of time parameter for activity $j$ and individual $i$ $a_{j}^{i}$ : amount of time available for the activity participation;

$a_{j}^{i}=\left\{\begin{array}{lr}\tau-2 * t_{w} & ; \text { for mandatory activities } \\ \tau-T_{w}-2 * t_{w} ; \text { for non - mandatory activitie }\end{array}\right.$ where:

$\tau$ : total daily time budget; from urban household survey this value is set to be equal to 16 hours

$t_{w}:$ travel time spend in the activity

$T_{w}:$ actual duration of activity

\subsubsection{Spatial Component- $a_{k}$}

The Accessibility-Benefit method requires a representative measure of the attractiveness of a location; high attractiveness provides better chances of satisfying the needs of individuals. This measure depends on the intensities of the various activities at the locations. For developing countries, the attractiveness of location is valued at the household level and given as: $a_{j k}=c \rho_{j} \omega_{j}$

where:

$a_{j k}$ : a finite non-negative real number representing a vector of attributes characterizing an activity $j$ at location $\mathrm{k}$

$\rho_{j}$ : the level of activity $\mathrm{j}$

$\omega_{j}$ : the weight attached to the activity

$c$ : the model calibration parameter $(c>0)$

The effect of income on spatial constraints is through the job locations offer opportunities for work to earn income or to improve skills through education in order to increase their earnings. The effect of income on accessibility is indirectly through the relative weight $\omega_{j}$. Explanation of activity attributes $\rho, \omega, c$ will be explained with actual values at section5.

\subsubsection{Integrated Accessibility-Benefit Model}

The benefit or utility of an opportunity is defined on the basis of Accessibility Benefit (BM) of an activity. The accessibility benefit model is used to define the utility function as follows [12]:

$B M_{j}^{k}=\exp \left[-\left(\frac{m}{\alpha I}+\frac{1}{v}\right) 2 x_{k}\right][c \rho \omega]_{\cdot j k} h^{\gamma}\left[\tau-\frac{2 x_{k}}{v}\right]^{\gamma}(10$

where:

$B M_{j}^{k}$ : index measure of accessibility benefit

$j \quad:$ activity type

$k \quad$ : activity location

$m \quad$ : monetary travel cost per $\mathrm{km}$

$\alpha I \quad:$ value of travel time per hour assigned by the individual having income $I$

$v \quad:$ speed of travel in $\mathrm{km} / \mathrm{hr}$

$x \quad$ : distance to the location in $\mathrm{km}$

$\rho \quad$ : level of activity (for example number of jobs)

$\omega \quad$ : attraction characteristics of the activity in the form of weight attached to the activity

$c \quad$ : the policy / model calibration parameter (c>0)

(8)

\section{Framework Methodology for Modeling Activity Destination Choice Model}

This work investigates the process required for developing Activity Destination Choice Model (ADCHM) based on the Activity-Based choice approaches. This framework is suitable for determining travel demand in urban areas of developing countries under different new policies and measures.

ADCHM results in much more realistic choice model outcomes. These outcomes have output files that look very much like a real mode/activity choice survey data in a course of a day. Modeling a full list of households with the same attributes avoids numerous aggregation 
partialities that arise in the conventional modeling frameworks. It also uses discrete choice modeling technology that greatly reduces the computational size of the model application problem. This allows the examination of virtually unlimited explanatory variables (household personal and social, modes, other alternatives attributes).

Figure 4 outlines the framework methodology which contains three main modules as follows:

Module 1: Disaggregate data process

Module 2: Parameter estimation process

Module 3: Travel Demand Aggregation Process

Each of modules consists of processes and algorithms to complete the desired tasks and collectively predict travel demand as describe below.

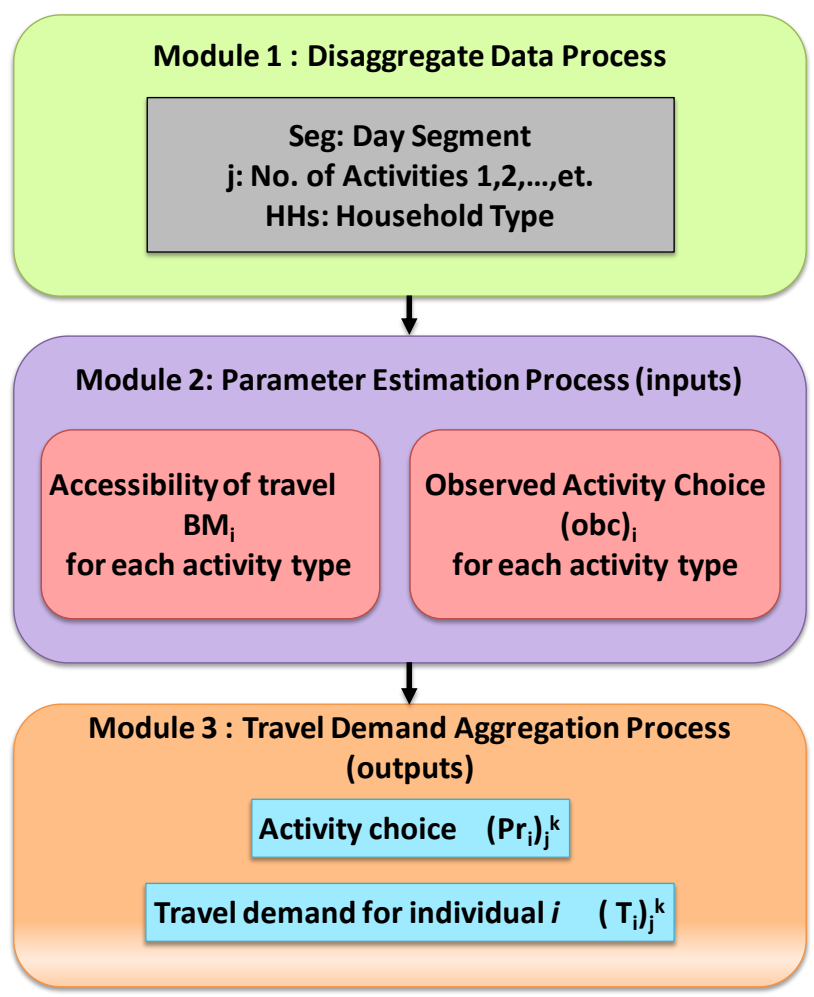

\section{Figure 4: Activity Destination Choice Model (ADCHM-PS) Framework}

\subsection{Module 1: Disaggregate Data Process}

This module consists of the data required from PortSaid questionnaire survey (revealed data). The output is in the form of a database containing inputs for the various stages of the modeling system. The individual type uses the household structure and the individual identification data to include four types of individual in collected data as ID1, ID2, ID3, and ID4. Income is the most important economic constraints. Thus, the sample was classified to $\mathrm{HH} 1$ and HH2. After disaggregation of collected data, the second step is to prepare the inputs of the model by choice model parameter estimation.

\subsection{Module 2: Parameter Estimation Process}

The individual vectors are the inputs of this step. These are used in specifying various model forms. The estimation of unknown model parameters is carried out for each model form. The output is the set of model parameters needed to estimate the individual probability of selection of various activities. The inputs are the two vectors for each individual; the estimated variable $B M_{j}^{k}$ and the observed choice vector $\left(o b c_{i}\right)_{j}{ }^{k}$.

\subsubsection{BM values for each activity type $\left(B M_{j}^{k}\right)$}

As described earlier, the accessibility benefit (BM) is defined as the index measure of accessibility of the activity for the individual, as explained earlier. In this way, the BM acts as the explanatory variable for modeling individual travel behavior. Therefore, the BM model must contain all the factors influencing the accessibility of the activity for the individual. The collected data provide the input for activity attraction parameters, $c$ and $\rho$. The household data is used for the parameters important from the point of view of decisions taken at the household level. These parameters are $I, \omega, h$, $\tau$, and $\gamma$. The activity dependent parameters are $\alpha, m, v$ and $x$.

\subsubsection{Observed choice value for each individual type $\left(o b c_{i}\right)_{j}^{k}$}

The individual daily activity diary provides the actual observed behavior of the individual during a typical day. It is possible to derive the individual's observed binary choice for any given activity. The output is the binary choice value for each individual in terms of the following parameter: $\left(\boldsymbol{o} b c_{i}\right)_{j}{ }^{\boldsymbol{k}}=1,2, \ldots$, et. for the activity being selected for multinomial regression analysis.

Table 1 shows an example of the multinomial choice vector (obc) $i$ for each segment of the day from actual questionnaires to be used in model application step. These data are the input data and the dependent variable which was entered to SPSS software and provided the model output.

Table 1: An Example from Data Sheet of The Multinomial Choice Vector (obc)i for each Segment of the Day 


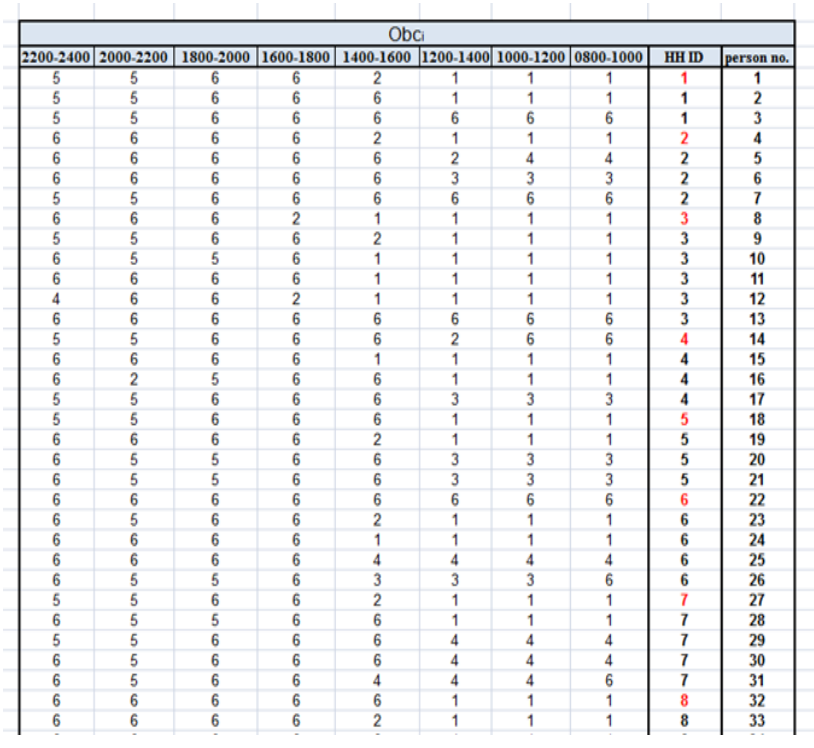

\subsection{Module 3: Travel Demand Aggregation Process}

This module is responsible for the determination of individual travel demand $\left(\mathrm{T}_{\mathrm{i}}\right)_{\mathrm{j}}^{\mathrm{k}}$ (aggregation process) as illustrated in Figure 5. The demand is estimated for different activities at each day segment day and each individual type.

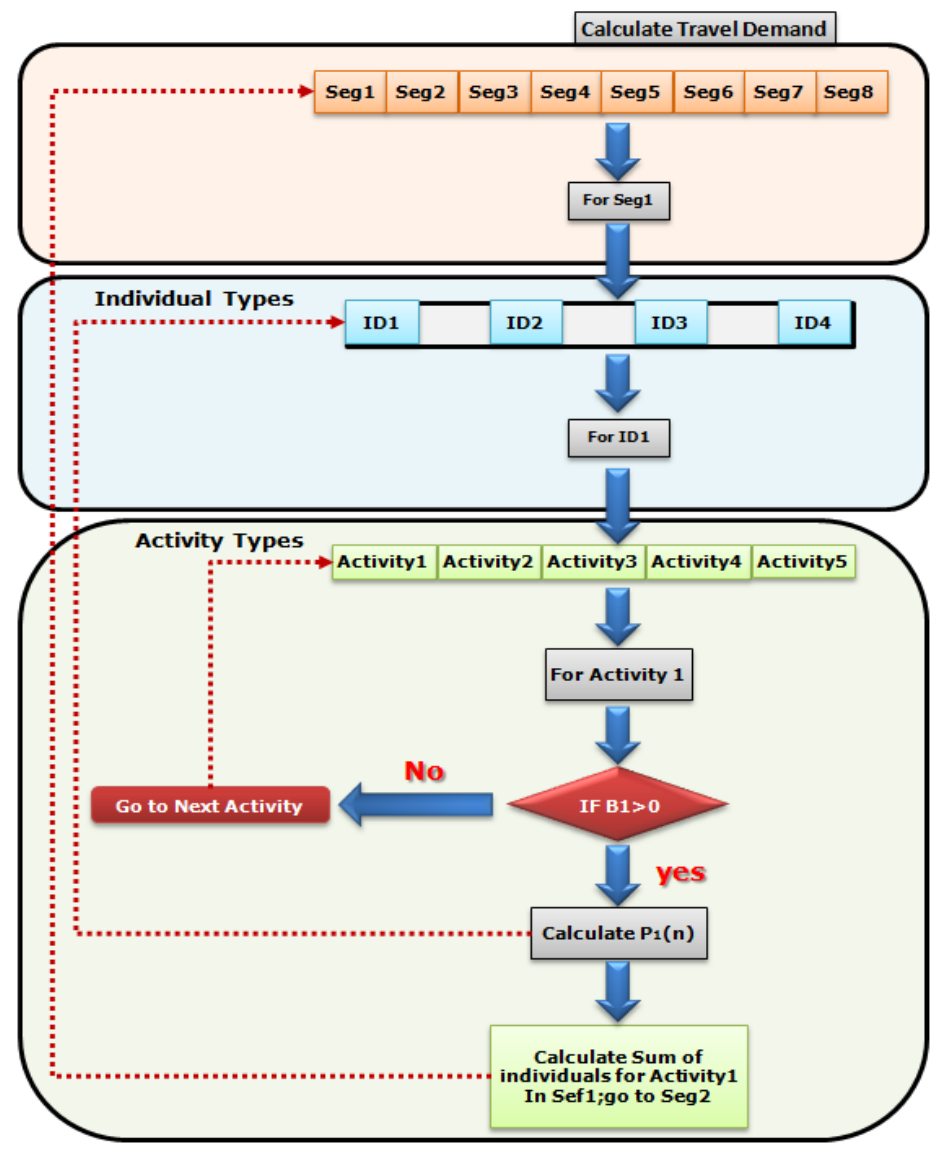

Figure 5: Travel Demand Aggregation Process

\section{Case Study - Port-Said City, Egypt}

Port-Said (PS) city plays a leading role in Egyptian trade because of the presence of Suez Canal and East of Port-Said Port. It has an area of $1,351.14 \mathrm{~km}^{2}$. According to administrative divisions of the city; the economies of its urban populations are trade and services business. It consists of seven zones as shown in Figure 6: El-Sharq,
El-Arab, El-Dawahy, El-Manakh, El-Zohor, Port Fouad, and the South area. The total population is 630,000 in all zones excluding south zone. South zone was excluded from the urban study area because it is out of intertransportation network service [16]. 


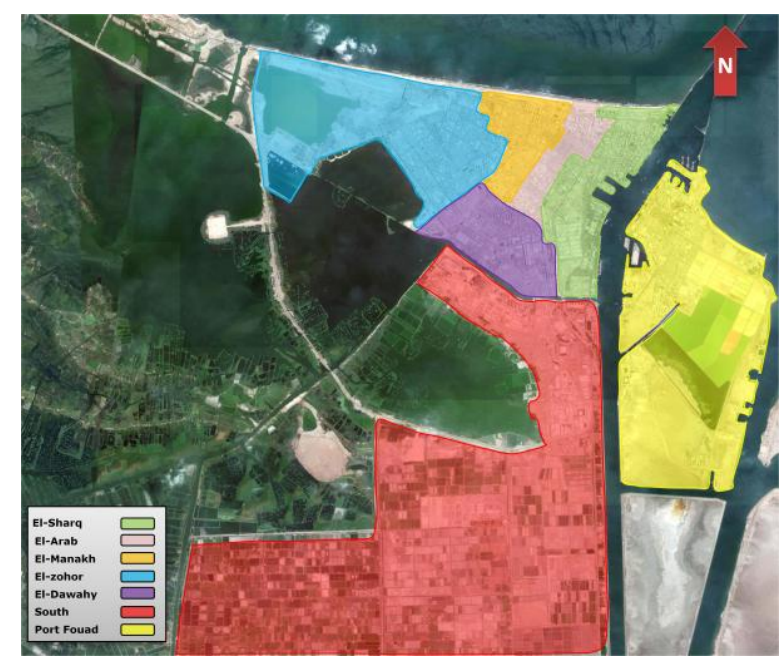

Figure 6: Administration Zones of Port Said city [16]

A comprehensive revealed field survey was carried out for PS based on a choice process. The choice of participation in an activity is defined as a function of the attributes of the individual and the household. The data collected are divided into two groups:

- Socio-economic data: household size, number of persons employed, household vehicle ownership, position (head, wife, first child, second child, etc.), age, and income.

- Activity participation data: activity types, locations, timings, duration, and frequency of travel.

The applied questionnaire is for 180 families. The analysis of the activity-travel patterns of PS population showed that a distinct behavior is existed within various times of the day which is a mutual attribute among all developing countries. The whole day (16 hour time duration excluded 8 hours existing at home) can be divided into eight time segments, the boundaries of which may be defined as the change points for a new pattern of behavior. On the basis of the available data, eight time segments (2-hours) may be defined as follows : 08001000 , 1000-1200, 1200-1400, 1400-1600, 1600-1800, 1800-2000, 2000-2200, and 2200-2400.

\subsection{Model Parameters Estimation}

The accessibility benefits model $B M_{j}^{k}$ estimation is based on the determining of different model parameters. Some of these parameters are obtained directly from the database, while the others need to be derived from basic definitions of the parameters. Detailed development of such parameters is given in the succeeding paragraphs.

\subsubsection{Value of Travel Time Coefficient $\alpha$}

A detailed study must be carried out to obtain a true estimate of the value of travel time coefficient $\alpha$. A method of estimating its value based on the concept of "generalized money expenditure" on travel was developed by Ali (2009) [15]. Based on the revealed data of Port Said urban area, $\alpha$ value is considered as presented in Table 2. As shown in the table higher values are considered for mandatory activities than for nonmandatory activities. This is due to the fact that travelers are afraid to spend money in less-importance activities such as entertainment (e.g. shopping) than in mandatory activities (e.g. work).

Table 2: Considered $\alpha$ Values for PS

\begin{tabular}{|l|c|c|}
\hline Activity Income & Low & High \\
\hline Mandatory & 1.33 & 1.5 \\
\hline Non-mandatory & 0.33 & 0.5 \\
\hline
\end{tabular}

\subsubsection{Level of Activity $\rho$}

The level of activity parameter $\rho$ considers the effect of availability of an activity. $p$ represents the level or intensity of an activity at a location, it can be expressed in the form of an array of attributes of each location separately as follows:

$\left(\rho_{j}^{k}\right)=f\left\{\left(X_{j}^{k}\right)_{l}\right\}$

where:

$\left(\rho_{j}^{k}\right)$ : level of activity $j$ at location $k$

$\left(X_{j}^{k}\right)$ : vector containing attributes of activity $j$ at location $k$

I $\quad: 1,2, \ldots$, I number of attributes used for activity $j$

For Port Said city, based on the collected data of the study area, a number of measures are defined to be used in the functional form:

$$
\rho=1 /\left(\exp ^{\text {measure }}\right)^{\wedge} 0.2
$$

The relevant measures defined by means for the relevant activity are used for each activity as defined in the collected data and summarized in Table 3.

Table 3: The Estimated Level of Activity Parameter $\rho$

\begin{tabular}{|l|c|c|c|c|c|c|c|}
\hline \multirow{2}{*}{ Activity } & \multirow{2}{*}{ Measure } & \multicolumn{6}{|c|}{ Zone } \\
\cline { 3 - 8 } & & $\mathbf{Z 1}$ & $\mathbf{Z 2}$ & $\mathbf{Z 3}$ & $\mathbf{Z 4}$ & $\mathbf{Z 5}$ & $\mathbf{Z 6}$ \\
\hline Work & No. of jobs & 0.44 & 0.25 & 0.95 & 0.32 & 0.24 & 0.63 \\
\hline
\end{tabular}




\begin{tabular}{|l|c|c|c|c|c|c|c|}
\hline University & No. of faculties & 0.20 & 0.21 & 0.12 & 0.04 & 0.05 & 0.32 \\
\hline School & No. of schools & 0.53 & 0.48 & 0.42 & 0.35 & 0.35 & 0.45 \\
\hline Shopping & No. of markets & 0.85 & 1.0 & 0.2 & 0.09 & 0.05 & 0.42 \\
\hline Leisure & No. of places & 1.0 & 0.2 & 0.02 & 0.04 & 0.05 & 0.42 \\
\hline
\end{tabular}

based on Equations 6 and 7 described earlier.

\subsubsection{Attraction Characteristics of the Activity $\omega$}

Since $\omega$ defines the attraction characteristics of the activity, its value is taken in the form of weights attached to the activity types. These weights are assumed for demonstration purpose suitable for urban areas characteristics. Actual values (for example primary school has higher weight for child less than 16 years than any other). The expression used is as follows:

$$
\omega_{\mathbf{j}}^{\mathbf{i}}=\frac{D_{\mathbf{j}}^{\mathbf{i}}}{\text { scale }_{\mathbf{j}}}
$$

where:

$\omega_{j}^{i}$ : attraction parameter for activity $j$ for the individual $i$ $D_{j}^{i} \quad$ : a dummy variable which is equal to 1 if activity $j$ is

relevant to individual $\mathrm{i} ; 0$ otherwise

scalej : the scale (a number between 1 and 5), for the activity $\mathrm{j}$ reported by the household for non-work activities; equal to 1 for work/school

For Port Said, the parameter $\omega$ represents the relevance of an activity to an individual type and considers how the individual would perceive the activity within the household context. The households are asked to rate the importance of each activity for their household. This variable was called 'scale' in the household questionnaire. In addition to this, each household was also asked to identify the individual responsible for carrying out the activity. These two measures provided the basis for the development of empirical values of the parameter $\omega$, to define attraction of an activity for each individual. Actual values had been derived from field data as shown in Table 4.

It is worth mentioning that measuring of utility parameter-h and Marginal utility of time parameter- $\gamma_{j}^{i}$ are
Table 4: Activity Relevance and Weighting for Person Types (scale)

\begin{tabular}{|l|c|c|c|c|}
\hline Activity & Male>21 & Female>21 & Child >16 & Child $<\mathbf{1 6}$ \\
\hline Work & 1.00 & 0.50 & 0.20 & 0.00 \\
\hline University & 0.00 & 0.20 & 1.00 & 0.00 \\
\hline School & 0.20 & 0.10 & 0.00 & 1.00 \\
\hline Shopping & 1.00 & 1.00 & 0.50 & 0.00 \\
\hline Leisure & 1.00 & 0.50 & 1.00 & 1.00 \\
\hline Other & 1.00 & 0.20 & 0.20 & 0.00 \\
\hline
\end{tabular}

\subsubsection{The Policy Parameter c}

The model calibration parameter $c(c>0)$ represents the development targets to be achieved in the activity levels available to the local population. For every type of activity, the value of $c$ can be estimated as a function of parameter $\rho$ as shown in Tables 5 and 6 . These are often set as goals in development master plans by national governments and local authorities in developing countries.

Values of c for shopping activity, for example, use the desired level of activity that a shopping place must be available within $0.5 \mathrm{~km}$ of each house. The value of $\mathrm{c}$ is therefore the highest for zone-2, where the shopping place was within $1 \mathrm{~km}$. This methodology identifies the flexibility of using the policy inputs in the travel demand models developed.

The measuring of utility parameter-h is determined using Equation 6 described earlier. The marginal utility of time parameters $\gamma_{j}^{\mathrm{i}}$ for mandatory and non-mandatory activities is determined using Equation 7 for each individual while $\mathrm{a}_{\mathrm{j}}^{\mathrm{i}}$ is estimated using Equation 8 .

Table 5: Example Values for Policy Parameter $C$ (Ali, 2009)

\begin{tabular}{|l|c|c|c|c|c|}
\hline Activity type & Activity & A level measure & Recent & Target & Value of $\boldsymbol{c}$ \\
\hline Mandatory & work & No. of jobs & 1 per 500 & 1 per 300 & $300 / 500$ \\
\hline Non mandatory & shopping & No. of shops & 1 per 5000 & 1 per 2500 & $2500 / 5000$ \\
\hline
\end{tabular}

Table 6: Estimated Values for Policy Parameter $\boldsymbol{C}$

\begin{tabular}{|l|l|c|c|c|c|c|c|}
\hline \multirow{2}{*}{ Activity } & \multirow{2}{*}{ Measure } & \multicolumn{5}{|c|}{ Zone } \\
\cline { 3 - 8 } & & $\mathbf{Z 1}$ & $\mathbf{Z 2}$ & $\mathbf{Z 3}$ & $\mathbf{Z 4}$ & $\mathbf{Z 5}$ & $\mathbf{Z 6}$ \\
\hline Work & Double current employment & 0.5 & 0.5 & 0.5 & 0.5 & 0.5 & 0.5 \\
\hline University & Increase current places & 0.25 & 0.1 & 0.1 & 0.04 & 0.05 & 0.5 \\
\hline School & Double current places & 0.5 & 0.5 & 0.5 & 0.5 & 0.5 & 0.5 \\
\hline Shopping & Within $\mathbf{0 . 5} \mathbf{~ k m}$ & 0.45 & 0.85 & 0.25 & 0.09 & 0.05 & 0.42 \\
\hline
\end{tabular}




\begin{tabular}{|l|l|c|c|c|c|c|c|}
\hline Leisure & Double current places & 0.5 & 0.5 & 0.5 & 0.5 & 0.5 & 0.5 \\
\hline
\end{tabular}

Since the BM of any activity defines the utility of the

\subsection{Estimation of Individual BMs}

The benefit or utility of choosing a specific activity (BM values) are estimated using Equation 10 and illustrated in Table 7. Binary and Multinomial logit models were used for daily activities performed by individuals [15]. For each time segment the model predicts individual probability of choosing one of the five activities. The five activities considered were: work, shopping, school, university, and Leisure.

Each model in the table predicts the probability of selection of a particular activity on the basis of the estimated model parameters. For example, in time segment-1, model for Work (choice 1) for ID1 (Male>21 years old) was used to estimate the probability of selection of Work activity. The probability of the remaining activities, Shopping and Leisure were found using the basic probability concepts. activity participation for the individual, it may be argued that increased accessibility benefit of activity Work would increase the travel demand of the Household Heads. The travel demand for the ID2 would be unaffected by any increase in accessibility benefit of activity Work. Furthermore, the increased accessibility benefit to School would increase the travel demand of ID3 more than ID4 as represented by the small value of constants in the university activity models. In urban areas, the school activity is mandatory with slight affect by changeable attributes.

Table 7: Estimated Logistic Regression Models

\begin{tabular}{|c|c|c|c|c|c|c|c|c|}
\hline \multirow{2}{*}{ mUE SEGMENT } & \multirow{2}{*}{$\begin{array}{c}\text { INDIMDUAL } \\
\text { TYPE }\end{array}$} & \multirow{2}{*}{ ACTIMTY } & \multicolumn{6}{|c|}{ PARAMEIERESTIUATES } \\
\hline & & & CONST. & Ba1 & Ean2 & Bin3 & Ban4 & Ban5 \\
\hline \multirow{4}{*}{$0800-1000$} & ID1 & 1 & -1.827 & 1.3184 & & & & \\
\hline & ID2 & 1 & -1.461 & 0.936 & & & & \\
\hline & ID3 & 4 & $\ldots .$. & & & & 0.485 & \\
\hline & ID4 & 3 & -2.34 & & & 2.66 & & \\
\hline \multirow{5}{*}{$1000-1200$} & ID1 & 1 & -2.013 & 0.505 & & & & \\
\hline & ID2 & 1 & -2.016 & 0.347 & & & & \\
\hline & & 2 & -2.021 & & 0.127 & & & \\
\hline & ID3 & 4 & ...... & & & & 0.48 & \\
\hline & ID4 & 3 & -2.34 & & & 2.66 & & \\
\hline \multirow{6}{*}{$1200-1400$} & ID1 & 1 & -0.68 & 0.205 & & & & \\
\hline & & 2 & -2.2 & & 0.178 & & & \\
\hline & ID2 & 1 & -0.663 & 0.337 & & & & \\
\hline & & 2 & -1.897 & & 0.083 & & & \\
\hline & ID3 & 4 & -0.34 & & & & 0.212 & \\
\hline & ID4 & 3 & -224 & & & 2.56 & & \\
\hline \multirow{4}{*}{$1400-1600$} & ID1 & 1 & -1.756 & 0.093 & & & & \\
\hline & ID2 & 1 & -2.89 & 0.147 & & & & \\
\hline & & 2 & -2.71 & 0.211 & 0.152 & & & \\
\hline & $\begin{array}{l}\text { ID3 } \\
\text { ID4 }\end{array}$ & & & & & & & \\
\hline \multirow{3}{*}{$1600-1800$} & ID1 & 2 & -4.31 & & 0.167 & & & \\
\hline & ID2 & & & & & & & \\
\hline & $\begin{array}{l}\text { ID3 } \\
\text { ID4 }\end{array}$ & & & & & & & \\
\hline \multirow{4}{*}{$1800-2000$} & ID1 & 5 & -124 & & & & & 0.152 \\
\hline & ID2 & 5 & -1.224 & & & & & 0.722 \\
\hline & ID3 & 5 & -2.45 & & & & & 0.987 \\
\hline & ID4 & & & & & & & \\
\hline \multirow{6}{*}{$2000-2200$} & ID1 & 5 & -0.115 & & & & & 0.292 \\
\hline & ID2 & 2 & -1.93 & & 0.157 & & & \\
\hline & & 5 & ........ & & & & & 0.549 \\
\hline & ID3 & 1 & -3.98 & -0.829 & & & & 0.21 \\
\hline & & 5 & -1.134 & & & & & 0.458 \\
\hline & ID4 & 5 & -0.94 & & & & & 0.457 \\
\hline \multirow{4}{*}{$2000-2400$} & ID1 & $\mathbf{5}$ & -1.244 & & & & & 0.62 \\
\hline & ID2 & 5 & -3.146 & & & & & 0.401 \\
\hline & ID3 & $\mathbf{5}$ & -1.345 & & & & & 0.093 \\
\hline & ID4 & & & & & & & \\
\hline
\end{tabular}

After calculating the probability, the resulted percents were multiplied by the number of individuals to calculate travel demand. Figures $\mathbf{7}$ to $\mathbf{1 1}$ show the overall estimated and observed travel demand for all activities during the eight segments of the day. Overall, the estimated travel demand for every activity is found to be fitted well as indicated by the high values of $R^{2}$ as the SPSS outputs. 
An increase of the travel demand for 'Work, School, and University' activities is observed in time segments 1 , 2 , and 3 with some extension for work activity in segment 4 as shown in Figures 7, 8 and 9. This seems to be logic during workday period from 8:00 to 2:00 pm and few cases extended to 4:00 pm which is called work timeout variation. 'Work and School' activities participate in two peaks in segment 1 and 3 which presents the trips from home to work/school in the morning and by the trips from home to other activities such as Shopping because household prefer to pick up his/her child to/from school.

As shown in Figure 10, Shopping has two peaks. The first is the major morning peak that executed by household with no work or who can take permission to go shopping and return to complete his/her work at segment 3 . The second is the minor evening peak at segment 7 for older people needing more rest.

Figure11 shows 'Leisure' activity, there is no participation for the first five segments and begins to appear in remaining day with high increasing in time segment 7 which is considered an appropriate time for the entertainment places accessibility.

Time segment 5 "between 4.00 to 6.00 am" shows 'at home' presence for all activities except for shopping that can be made by household after work because of the difference of work time out. These traditions are widely known in developing countries.

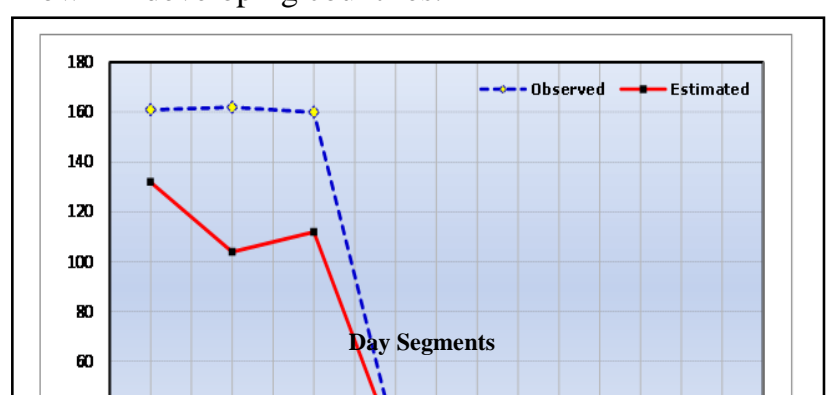

Figure 8: School Activity Observed/Estimated Travel Demand

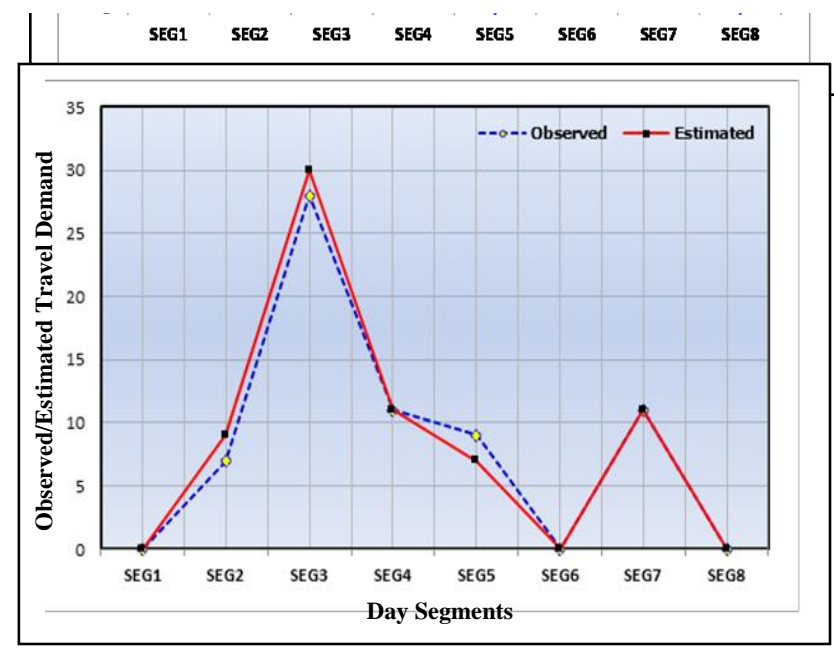

Figure 10: Shopping Activity Observed/Estimated Travel Demand
हैं

Figure 7: Work Activity Observed/Estimated Travel Beymanghts

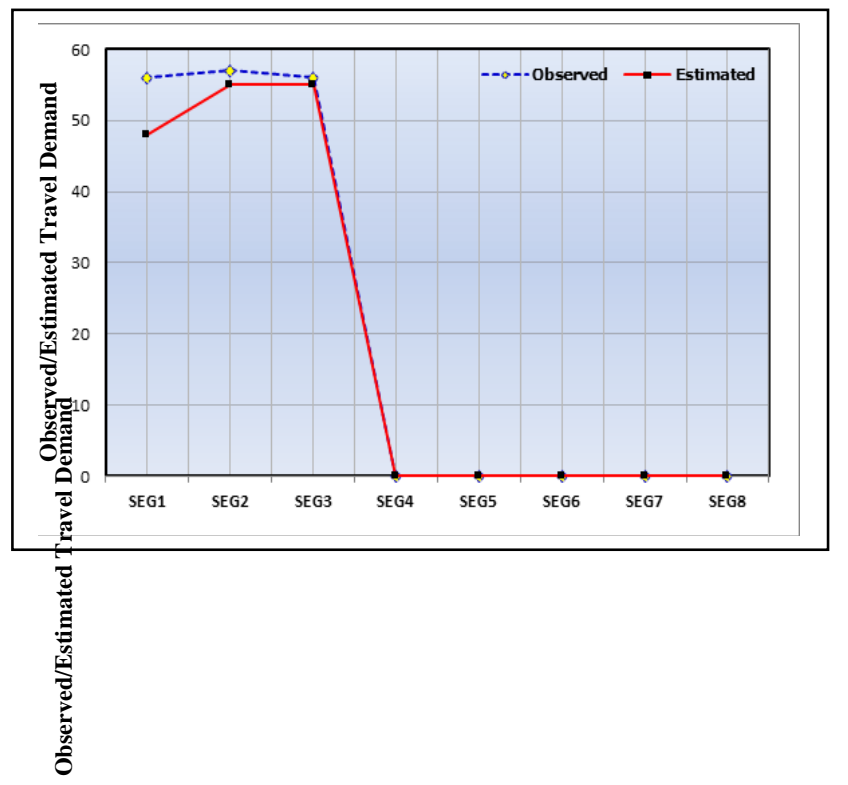

Day Segments

Figure 9: University Activity Observed/Estimated Travel Demand

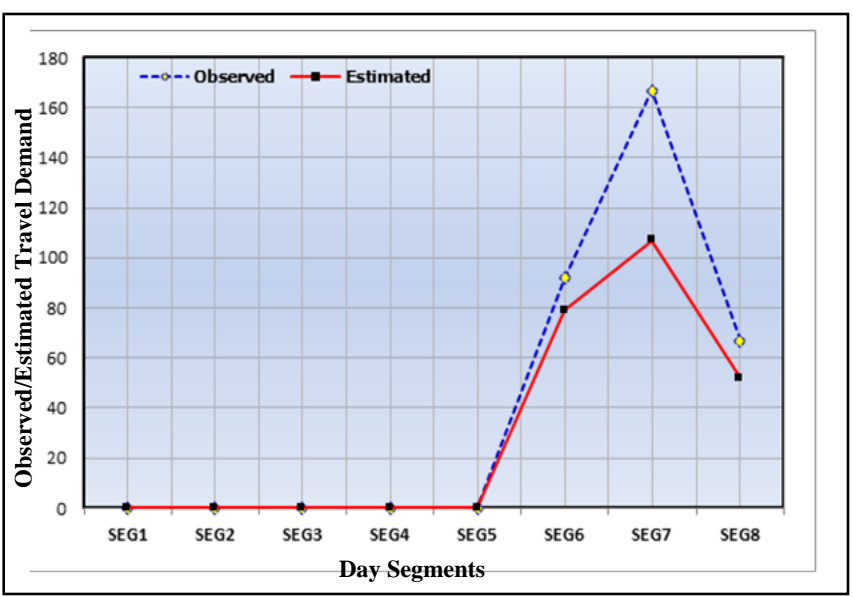

Figure 11: Leisure Activity Observed/Estimated Travel Demand 
The daily activity pattern type of each household member by two types of activities (mandatory and nonmandatory) of two different income level families are presented in Figures 12 and 13.

For HH1 (high income families), as shown in Figures 12, ID 1 (Father), goes to work at 7:00 AM and escorts the ID4 (younger child) to school. He leaves work at 15:00 PM. ID3 (Older child) goes alone to the university from 8.00 AM to 16.00 PM. Non- mandatory activities varies from one to other because it influenced by socioeconomic characteristics. Shopping is a vital activity that made by ID1 after work and escorting child from school and by ID2 (Mother), in the evening, when large malls are available it is akin to a leisure activity. Leisure activity could happen by ID 1 and ID3 during the evening period from 20.00 PM to 22.00 PM, or perhaps not take place at all.

Figure $\mathbf{1 3}$ is an example of $\mathrm{HH} 2$ (low income families); the two parents share the responsibility of escorting their children and of making shopping. ID2 works half a day in the morning while ID1 works two periods. In the morning, she goes to work at 7.00 AM; while ID1 escorts the younger child to school whereas ID3 can go alone to the university from 8.00 AM to 16.00 PM. ID1 goes shopping immediately after bringing ID4 from school after work. Then the family spends time together at home starting from 15.00 to 19.00 PM until he needs to go to work, again in the evening, to pay their demands.

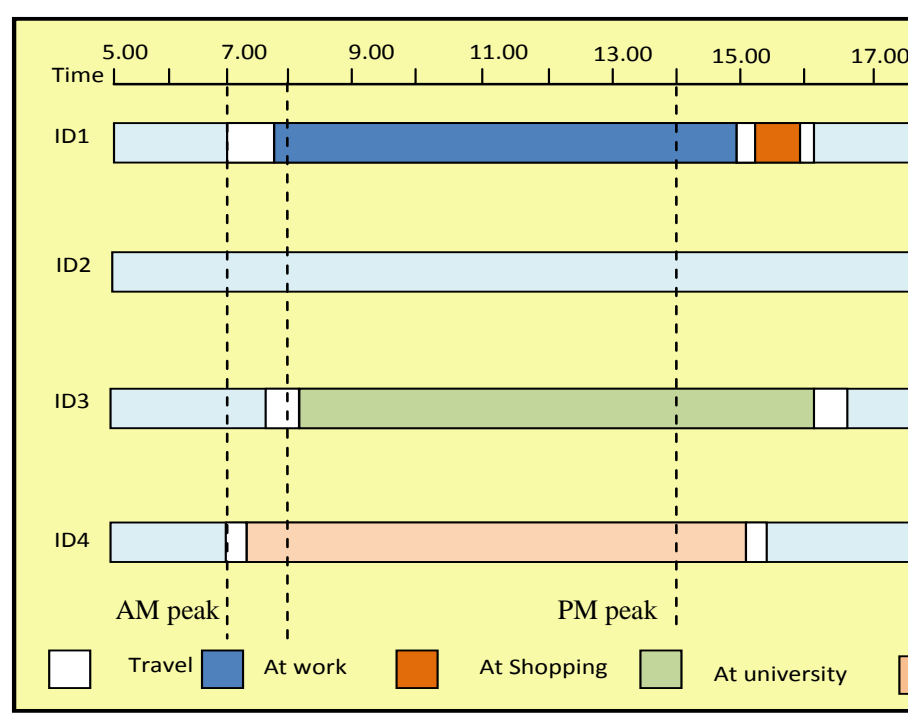

Figure 12: High Income Family's Activity Schedule with Mandatory and Non-Mandatory Activities in PS

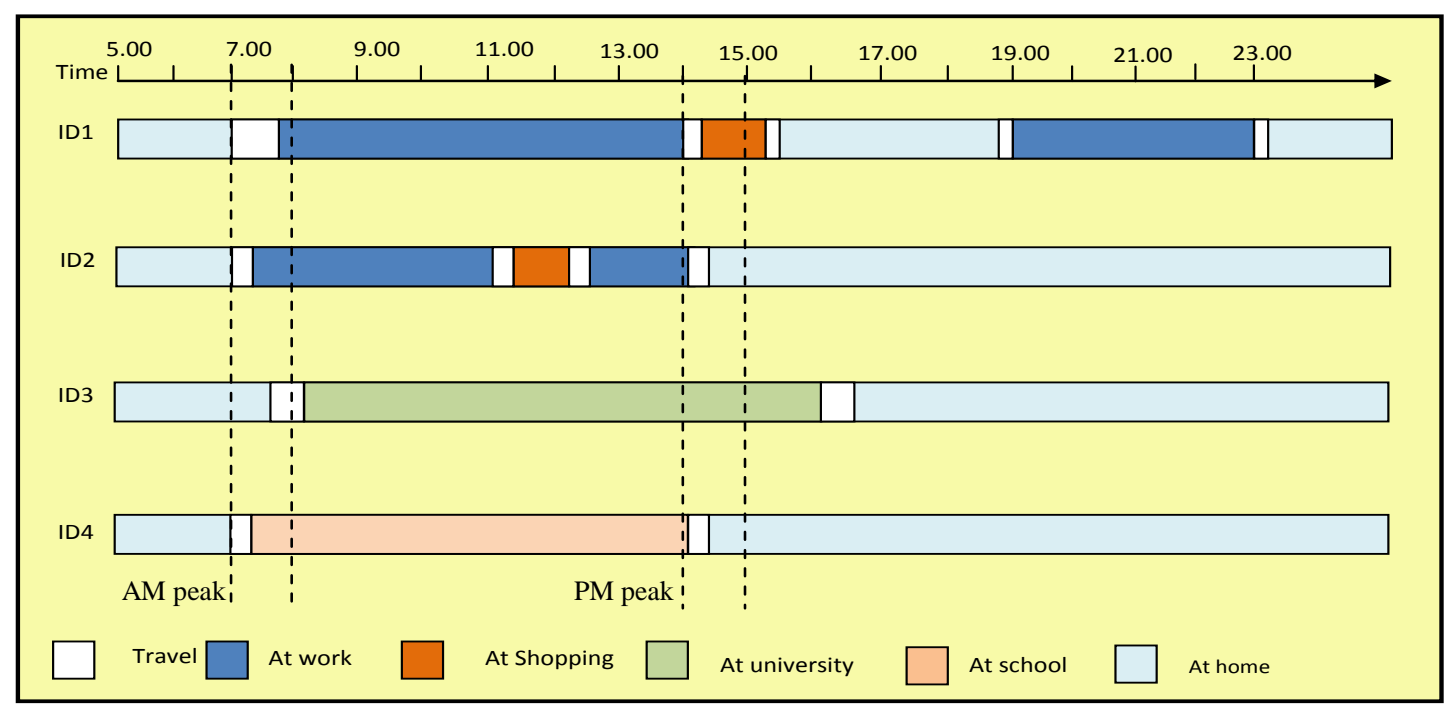

Figure 13: Low Income Family's Activity Schedule with Mandatory and Non-Mandatory Activities in PS 


\section{Models' Sensitivity to Different Demand Management Policies}

The types of questions being asked of travel demand models are expanding well beyond mere traffic projections and public transport ridership. Decisionmakers are now concerned about the technical assessment of the effectiveness of different policies such as decreasing travel time (public transport-oriented development), improving income level for poor, and restricting car use. The activity-based modeling approach has emerged as a potentially more suitable tool for answering these types of questions than the traditional trip-based approach. When assessing the relative merits of these two types of modeling approaches, one must make the assessment based on not only how well the models replicate observed travel conditions, but also the models' sensitivity to different demand management policies and strategies.

The impact of income level increase on the utility of choosing a specific activity (BM values) has been examined with three hypothetical scenarios: $10 \%, 20 \%$, and $30 \%$ increase in income level. Figure 14 shows examples at $\mathrm{BM}=0$ and $\mathrm{BM}=5$, the cause of the increase in income levels when compared with the real situation. As expected, the impact on mandatory activities is minor when compared to the impact on the nonmandatory activities. $30 \%$ increase in income level, however, showed clear impact on the mandatory activities when compared to the other scenarios (10\% and 20\%). This is due to the fact that in developing countries females might stay at home when sufficient income is ensured for the family.

For the non-mandatory activities, 10\%, 20\%, and 30\% increases in the income level have significant impact on the percentage of individual participation. At $\mathrm{BM}=0$, a decrease of about $50 \%$ of the percentage of individual participation is emerged at $30 \%$ increase in income level while at $\mathrm{BM}=5$, an increase of about $18 \%$ of the percentage of individual participation is appeared at the same increase in income level. This is clear as in developing countries poor households are forced to not perform non-mandatory activities (such as entertainment activities) as a result of the extreme low income levels.

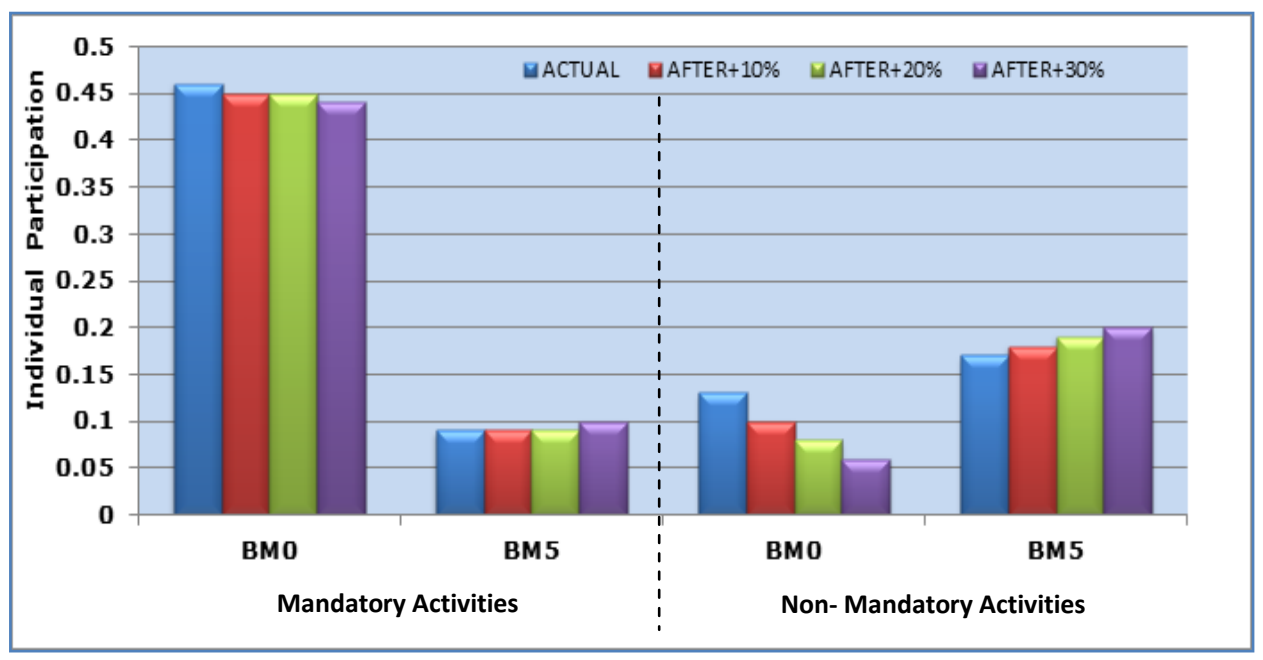

Figure 14: Impact of Income Level Changes on Mandatory and Non-Mandatory Activities

Figures 15 shows the effect of decrease in travel time by $10 \%$ and $30 \%$ as a hypothetical situation for overall improving the traffic condition in PS for the mandatory activities. There is no sturdily effect of travel time decreasing on mandatory activities preference because of the motive that forces to do the activity is still approximately the same. As shown in the figure the impact of $10 \%$ reduction in the travel time is minor when compared to the $30 \%$ reduction in the travel time. On the other hand the low utilities (BM 1-4) slightly decrease while high utilities (BM >4) slightly increase if compared to the actual situation with the improvement of the travel time. This is logic behavior since the mandatory activities have to done even though the travel duration is high.

In contrary to the mandatory activities, the reduction of travel time showed higher impact for non-mandatory activities as shown in Figure 16. 30\% improving on the travel time shows clear impact of the BM values with about $50 \%$ increase at $\mathrm{BM}$ values $=4 \& 8$ and about $90 \%$ decrease at $\mathrm{BM}=4$. This seems to be logic behavior since the nonmandatory activities are highly reliant to the travel duration. 


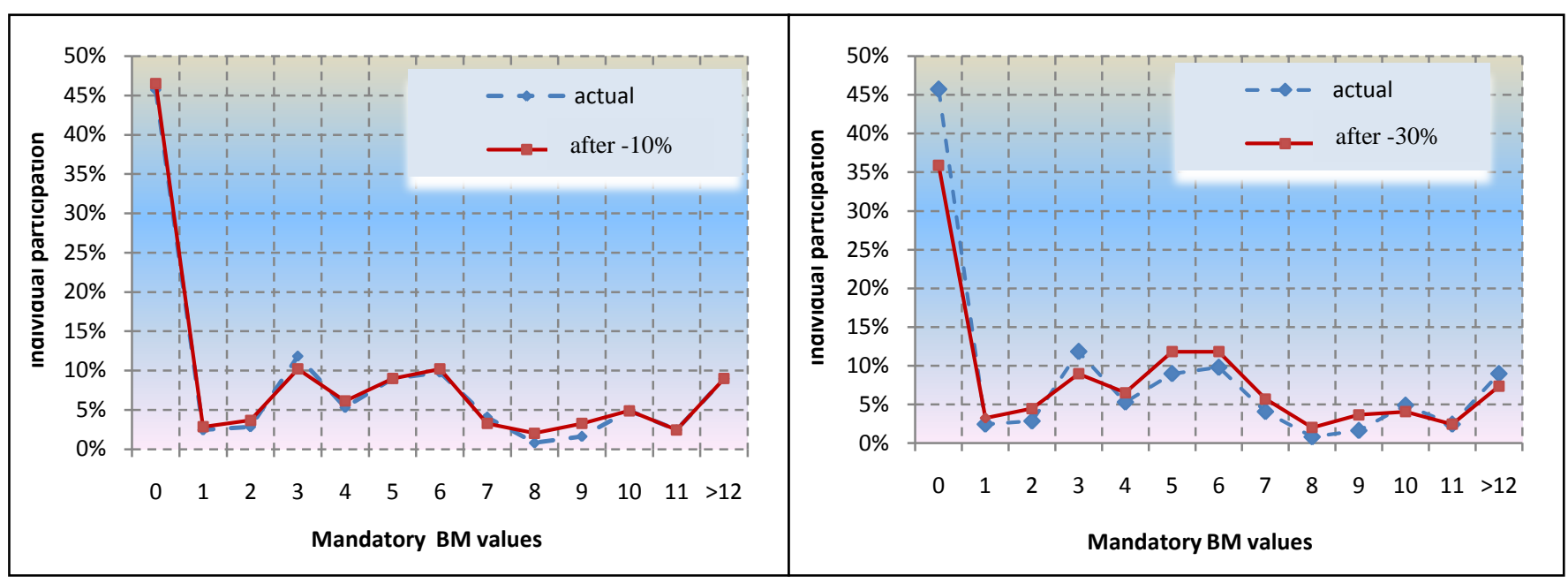

Figure 15: Impact of Travel Time Improvements on Mandatory Activity Participation

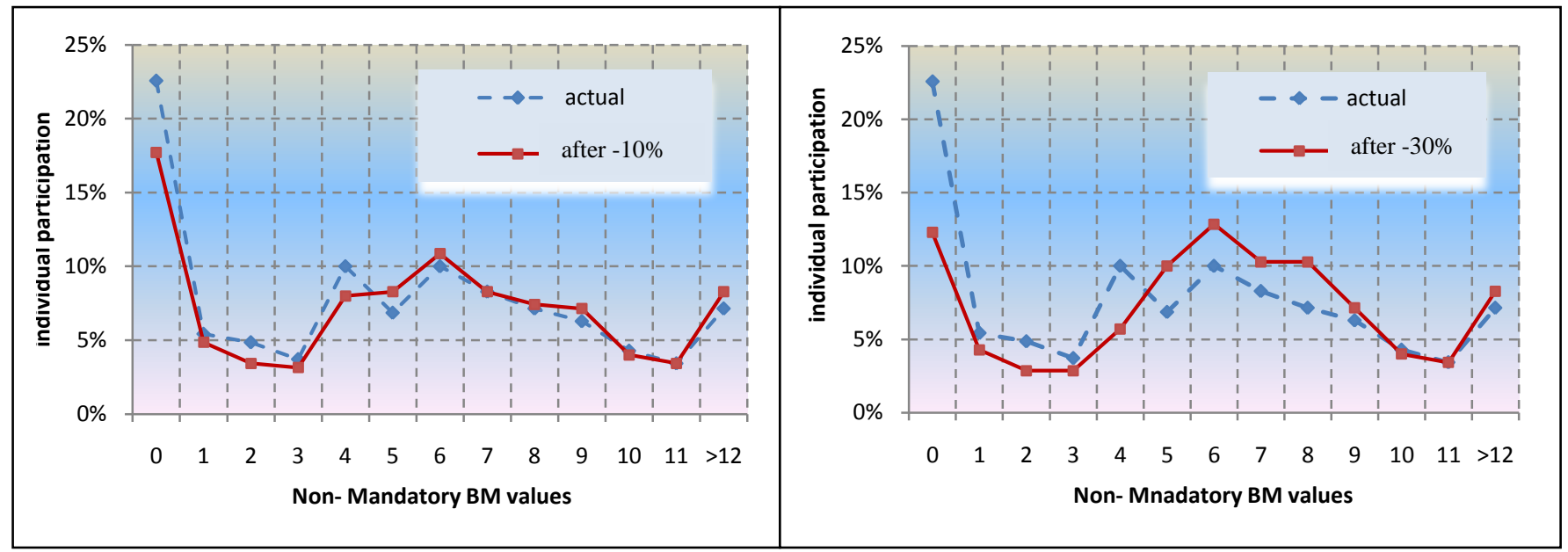

Figure 16: Impact of Travel Time Improvements on Non-Mandatory Activity Participation

The impact of car ownership on the utility of choosing a specific activity (BM values) has been examined as presented in Figure 17. As a result of the absence of a high quality public transport system in PS, the increase of car ownership showed high impact on leisure trips by cars with an increase of about $250 \%$ when comparing households owning 0 cars with those who own 2 cars per household. Clear impact is also showed for different mandatory activities with increases of about $160 \%$ in work activities, $60 \%$ in university activities, $150 \%$ in school activities, and $110 \%$ in shopping activities when comparing households owning 0 cars with those who own 2 cars per household. 


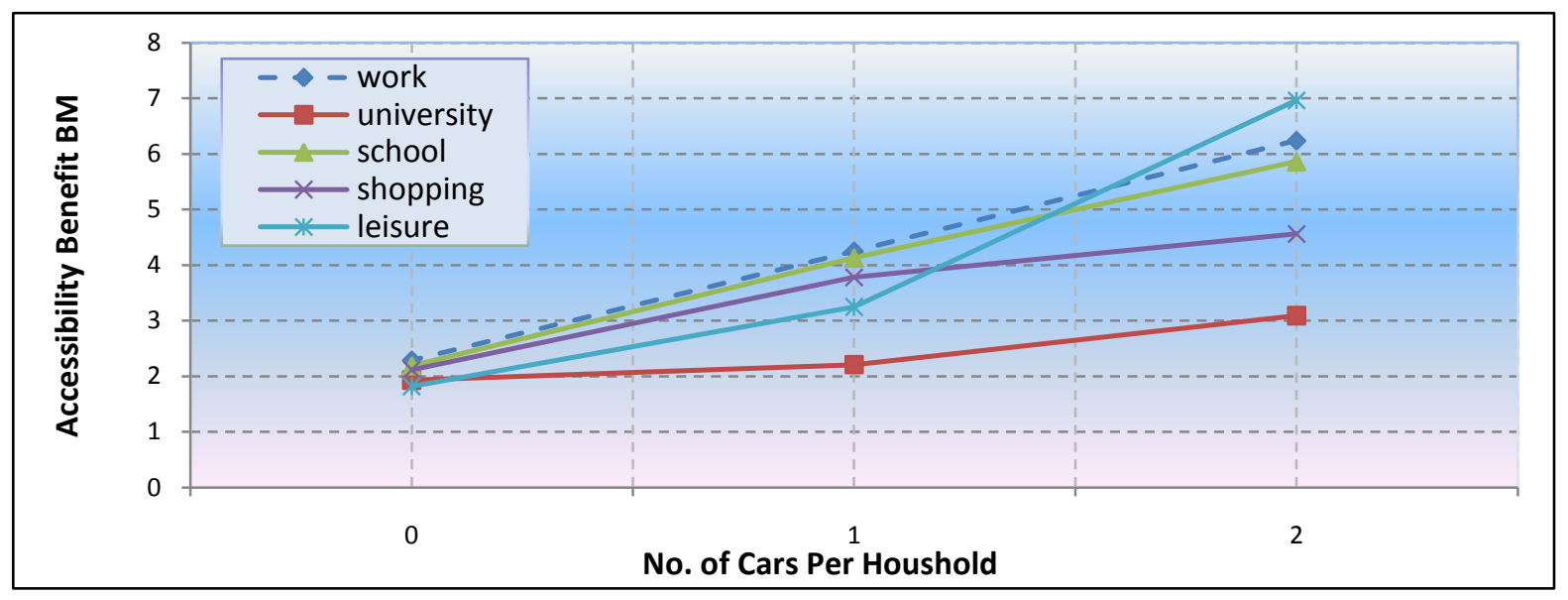

Figure 17: Impact of Car Ownership on the Accessibility Benefit (BM)

\section{Conclusions}

This study is concerned with using the accessibility concept to investigate the utility function of the activity destination choice of Port Said (PS) City in Egypt. It investigated the process required for developing Activity Destination Choice Model (ADCHM) based on the Activity-Based approaches which deals with a travel as a derived demand from the need to pursue activities distributed over space and time. Also it used discrete choice modeling technology that greatly reduces the computational size of the model application problem.

Different characteristics such as time, cost, and income level are analyzed for the model defining the real situation of PS transport system.

The main findings of this research were as follows:

- From the sketched activity pattern, in poor families, the two parents share the responsibility whereas the father has much responsible for making mandatory activities in high income level families. Shopping is a vital activity that made by the father after work. It influenced by socioeconomic characteristics.

- The impact of income level is minor in mandatory activities when compared to the impact on the non-mandatory activities. $30 \%$ increase in income level showed clear impact on the mandatory activities when compared with other scenarios (10\% and $20 \%)$.

- There is no sturdily effect of travel time decreasing on mandatory activities participation, but it showed higher impact on non-mandatory activities participation. Low utilities (BM 1-4) slightly decrease while high utilities $(\mathrm{BM}>4)$ slightly increase if compared with the actual situation with the improvement of the travel time.
- BM values increase of about $160 \%$ in work activities, $60 \%$ in university activities, $150 \%$ in school activities, and $110 \%$ in shopping activities when comparing households owning 0 cars with those who own 2 cars per household. This is due to the absence of a high quality public transport system in PS.

Finally and based on the above results, the model approved to be sensitive to different measures and hence it can be used as an effective informative tool to the decision makers after calibrating parameters for the study area.

\section{References}

[1] Tiglaon ,"Towards Integrated Urban Models for Developing Countries: Modeling Households and Location Choices Using Spatial Micro simulation Approach", National Center for Transportation Studies, University of the Philippines Diliman, 1101 Quezon City, Philippines, 2003

http://www.easts.info/2003journal/papers/2775.pdf

[2] Arentze, T.A., and Timmermans H.J., Albatross Version 2 "A Learning-Based Transportation Oriented Simulation System", European Institute of Retailing and Services Studies, Eindhoven, the Netherlands, 2010

[3] Willigers J, Floor H, van Wee B, "Accessibility indicators for location choices of offices: an application to the intraregional distributive effects of high-speed rail in the Netherlands", Environment and Planning A 39(9) 2086 - 2098, 2007

[4] Odoki J. B. ; Kerli H.; and Fabio S., "An Integrated Model for quantifying Accrssibility-Benefit in developing Countries", Dep. of Civil Engineering, University of Trieste, 34127 Trieste, Italy, 2001

[5] Arentze T., Timmermans H., and Hofman F., "Data Needs, Data Collection, and Data Quality Requirements of Activity-Based Transport Demand Models", Workshop 
on Modeler's Needs on TRB Transportation Research Circular E-C008, 2009

[6] Morrisp J. M., and Wigan M. R., "Accessibility Indicators for Transport Planning". Australian Road Research Board, 500 Burwood Highway, Vermont South. Victoria, Australia, 1978

[7] Shahin M., "Policy Sensitive Travel Demand Modeling Policy Sensitive Travel Demand Modeling with Emphases Report on Application and Future Research Data", State of the Art, Faculty of Engineering Alexandria University, 2012

[8] Kitamura R., "Applications of Models of Activity Behavior for Activity Based Demand forecasting" Department of Civil Engineering Systems, Kyoto University, Kyoto 606-01, Japan, 1996

[9] Hagerstrand T., "Space, Time, and Human Condition: In Dynamic Allocation of Urban Space". Saxon House, Lexington Books, DC Health, Massachusetts, USA, 1975

[10] Burns L.D., "Transportation, Temporal, and Spatial Components of Accessibility". Lexington Books, DC Health and Company, Massachusetts, USA, 1989

[11] Odoki J. B. , "Accessibility-Benefits Analysis as a Tool for Transportation Planning in Developing Countries. PhD. Thesis, University of Trieste, Polytechnic of Milan, Italy, 1992

[12] Odoki J. B. , "An integrated approach to rural accessibility planning in developing countries: accessibility-benefit model", Dep. of Civil Engineering, University of Trieste, Italy, 1998

[13] Odoki J. B., "Applications of the integrated accessibility-benefit model in rural accessibility planning in developing countries", Dep. of Civil Engineering, University of Trieste, Italy, 1998a

[14] Ali M., "An Accessibility-Activity Based Approach for Modeling Rural Travel Demand" A thesis submitted to The University of Birmingham, 2001

[15] Ali M., "Household Accessibility Analysis in Developing Countries Using Time-Space Prism", Ned University Journal of Research, Vol VI, NO. 1, Karachi, Pakistan, 2009

[16] Wikipedia Foundation (Free-Content Encyclopedia),[online], Retrieved, 09/12/2013 http://en.wikipedia.org/wiki/Port_Said_Governorate 